\title{
Focusing lung transplant: physiological and antioxidant responses and effect of allopurinol to ischemia- reperfusion oxidative stress under different inspired oxygen concentrations
}

\author{
Silva FM ${ }^{1}$, Silveira $\mathrm{RJ}^{1}$, Cardoso $\mathrm{JJ}^{1}$, Fabíola $\mathrm{S}^{2}$, Parisotto $\mathrm{EB}^{2}$, and Wilhelm Filho $\mathrm{D}^{2 *}$ \\ ${ }^{1}$ Departamento de Cirurgia/CCS, Universidade Federal de Santa Catarina, Florianópolis, SC, Brazil \\ ${ }^{2}$ Departamento de Ecologia e Zoologia/CCB Universidade Federal de Santa Catarina, Florianópolis, SC, Brazil
}

\begin{abstract}
Background: To evaluate the effect of alopurinol after lung ischemia-reperfusion (IR) injury under ventilation with different inspired oxygen concentrations ( 0.21 and $1.00 \mathrm{pO} 2)$ on physiological responses and tissue damage and antioxidants present in lung parenchyma.

Methods: Sixty Wistar rats were randomly allocated to six groups. Group 1 or control group (G1), Groups 2 and 3 (G2 and G3) animals ventilated during ischemiareperfusion with 0.21 and $1.00 \mathrm{pO}$, respectively. The three other groups (G1A, 2A and 3A) were pre-treated with $100 \mathrm{mg} / \mathrm{kg}$ allopurinol and submitted to similar procedures as groups 1, 2 and 3, respectively. The model used was normothermic ischemia-reperfusion in situ. Duration of ischemia and reperfusion was 30 and 10 minutes, respectively. Outcome measures included mean systemic arterial pressure ( $\mathrm{SAP})$, partial pressure of oxygen/inspired fraction of oxygen (PaO2/FiO2) ratio, lung wet/dry weight ratio, and markers of oxidative stress in lung parenchyma, such as levels of thiobarbituric acid reactive substances (TBARS) and reduced glutathione (GSH), as well as activity of catalase (CAT) and glutathione peroxidase (GPx).

Results: After IR at normoxia $(0.21 \mathrm{pO} 2)$ ventilation were detected a decreased SAP, higher $\mathrm{PaO} 2 / \mathrm{FiO} 2$ ratio, lower pulmonary edema, and also attenuated lung damage measured as markers of oxidative stress (lower TBARS and higher GSH levels) compared to hyperbaric ventilation (1.00 pO2). Animals pretreated with allopurinol revealed decreased values in SAP (G2xG2A and G3xG3A), in the ratio PaO2/FiO2 (G3xG3A), in TBARS levels and GPx and CAT activity (G3xG3A), while showing a significant increase in wet/dry weight ratio (G3xG3A).

Conclusions: Ventilation at normoxia compared to hyperoxia showed better physiological responses (decreased SAP, higher PaO2/FiO2 ratio, lower pulmonary edema) as well as considering the oxidative stress markers in lung parenchyma (lower TBARS and higher GSH levels) after IR. Pretreatment with allopurinol was able to improve all these parameters, including the responses of antioxidant enzymes. Therefore, ventilation under normoxia and use of allopurinol should be recommended for lung transplantation and organ preservation to attenuate IR injury in lung.
\end{abstract}

\section{Introduction}

Relatively high indices of morbidity and mortality usually accompany organ transplantation including lung transplant [1-5]. Ischemia-reperfusion (IR) and its associated injury is a complex phenomenon present in atherosclerosis, trauma, pulmonary embolism, and surgical procedures, such as cardiopulmonary bypass and lung transplant [6]. Reactive oxygen species (ROS) and reactive oxygen species (RNS) overgeneration have been associated with IR injury in different organs [3-5,7-11]. Several characteristics and consequences of IR pathological events are present in different organs and tissues, including lung, however ROS overgeneration and the consequent oxidative stress (OS) seem to be a common response always present in such cases [7-14].

Other consequences of IR injury particularly in lungs are also involved, as the onset of an inflammatory process, activation of neutrophils, platelets, cytokines, and the complement system, endothelial cell damage, increased vascular permeability, among several other biochemical and histological processes $[3,5,13,14]$. Nevertheless, contrasting with other tissues, lung is the solely organ that cope ischemia avoiding hypoxic conditions due to the proximity of high tensions of oxygen present in the alveoli [5]. In addition, the lung interface, which is characterized by a very delicate structure of the alveolar-capillary membrane, faces a huge damage associated to the deleterious IR process, including the procedure of lung transplant, especially in critically ill patients [15].

Regarding OS In different organs and tissues associated to the IR process, levels of lipoperoxidation and protein carbonyls among other OS markers are increased, which are detected after distinct periods of ischemia (minutes or hours) followed by different periods of reperfusion [14,16-18]. Also, cytochrome P450 seems to be the cytosolic component associated to the increased of mitochondrial hydrogen peroxide concentrations production and the related IR-

Correspondence to: Danilo W. Filho, P.O. box 12, Rua Major Generoso 182, 88680 970 Bom Retiro, SC, Brazil, Tel: +55-48-999697146; E-mail: dawifi@ccb.ufsc.br

Key words: lung, ischemia/reperfusion, reactive oxygen species, oxidative stress, allopurinol, antioxidants

Received: December 10, 2017; Accepted: December 27, 2017; Published: December 30, 2017 
cell damage [18]. In addition, a massive superoxide production is produced during the reperfusion period, thereby favoring a severe OS condition [16].

The severity of OS and the consequent damage to important structures and molecules seem to depend either on the time of ischemia $[19,20]$ and/or the time of reperfusion $[10,11,19]$. Anyway, ROS overgeneration is strongly associated with reperfusion, i.e., when oxygen resumes to organs and tissues, thereby allowing the restitution of oxidative metabolism, the so-called oxygen paradox or the dual effect of oxygen occurs [14]. Singlet oxygen (1O2), hydrogen peroxide $(\mathrm{H} 2 \mathrm{O} 2)$, superoxide anion $(\mathrm{O} 2 \bullet-)$ and hydroxyl radical $(\bullet \mathrm{OH})$ and other ROS and RNS are increased during IR, while the activity of main antioxidant enzymes, such as SOD, CAT and GPx, as well as important chain-breaker antioxidants (vitamin E, GSH and others) are decreased [14-20]. Therefore, the inactivation or decrease of these important enzymes combined with the lowering of important antioxidants lead to a severe OS condition [14].

The antioxidant efficacy of allopurinol in protecting different tissues and organs regarding IR-related damage is well documented in the related literature [21-26]. However, as far as we know, no study on the effect of allopurinol was carried out yet considering different ventilation conditions (normoxia and hyperoxia) on several OS markers in lung parenchyma after IR.

\section{Material and Methods}

Sixty Wistar rats were randomly distributed in six groups ( $\mathrm{n}=10$ animals each; weight between 300-355 g) as follow: Group 1 was the control group (G1), in group 2 (G2) the animals were ventilated at normoxia ( $\mathrm{pO} 2=0.21 \mathrm{~atm}$ ) during the process of IR (under normothermy $-19-23^{\circ} \mathrm{C}$ in situ, with ischemia of $10 \mathrm{~min}$ of duration followed by reperfusion of $30 \mathrm{~min}$ of duration), while in group 3 (G3) the animals were ventilated at hyperoxia $(\mathrm{pO} 2=1.0 \mathrm{~atm})$ during IR. To verify the effect of pretreatment with allopurinol ("A"), a dose of $100 \mathrm{mg} / \mathrm{kg}$ ) was administered by gavage $24 \mathrm{~h}$ before (pre-operatory) the experiments in animals from groups G1A, G2A and G3A. The present study was approved by the Ethics Committee on Animal Use of the Federal University of Santa Catarina, and was carried out in accordance with the Declaration of Helsinki and the European Communities Council Directive (86/609/EEC)..

\section{Experimental design and surgical procedures}

As physiological parameters, the systemic arterial pressure (SAP), the partial pressure of oxygen and the inspired oxygen fraction ( $\mathrm{pO} 2 /$ $\mathrm{FiO} 2)$ ratio, were monitored and recorded during the experiment in all six groups. The animals received pre-anesthesia (atropine 0.25 $\mathrm{mg} / \mathrm{kg}$ ), followed by anesthesia. Anesthesia consisted of a mixture of pentobarbital $3 \%$ and chloridate of 2-(2,6-xilidino)-5,6-dihydro$4 \mathrm{H}-1,3$-tiazina in a proportion of $10: 1$, administered subcutaneously $(0.1 \mathrm{ml} / 100 \mathrm{~g}$ weight$)$, followed by cervical tracheostomy, tracheal intubation for the mechanical ventilation (Harvard 683 device), at a rate of 80 ventilations/min, the air volume calculated according to Kleinman and Radford (1964), taken into consideration the animal weight. Next, a median laparotomy was carried out to introduce a catheter in the abdominal aorta for the use of heparine $(0.5 \mathrm{ml}$ saline $0.9 \%$ containing $0.02 \mathrm{ml}$ of heparine $5.000 \mathrm{U} / \mathrm{ml}$ ), followed by blood collection, as well as trans-operatory monitoring of the physiological parameters SAP and pO2. A ventilation system was connected with a nasogastric tube set between the aortic catheter, the latter fulfill with saline solution. Another segment was intercalated to a manometer to evaluate the room $\mathrm{pO} 2$ (measured in $\mathrm{mmHg}$ ). An anterior bilateral thoracotomy was carried out with the sternum transection. A microcirurgy procedure allowed the dissection of the left lung thread (hilus pulmonis sinister) to separate the left pulmonary artery and vein, which were kept pinched during the ischemia period regarding the groups G2, G3, G2A and G3A (left ischemic lung). As mentioned before, during the ischemia-reperfusion periods, the lungs were ventilated either with a $\mathrm{pO} 2$ of $0.21 \mathrm{~atm}$ (normoxia) or $1.0 \mathrm{~atm}$ (hyperoxia).

After finishing the experiment, which last approximately $100 \mathrm{~min}$, lung was irrigated with saline through the ligature of both cava veins (vena cava cranialis and caudalis), partial section of the aortic arch (arcus aortae), catheterism of the right atrium (atrium dextrum), and a slow injection of saline at room temperature were carried out. Next, pneumonectomy was performed in left and right lungs causing animal death. The schematic representation of the experimental design is in Figure 1.

\section{Physiological measurements}

The ratio between wet/dry weight in the left ischemic lung was measured by evaluating the weight of a portion of the left lung submitted to ischemia in natura (wet weight) and its relation with the same portion after drying for $4 \mathrm{~h}$ at $60^{\circ} \mathrm{C}$, which values were expressed in grams (g). The systemic arterial pressure (SAP) was performed using a manometer, the values expressed in $\mathrm{mmHg}$. The systemic arterial presssure $\left(\mathrm{PO}_{2}\right)$ and its relation with the inspired oxygen fraction $\left(\mathrm{FiO}_{2}\right)$ was measured by arterial gasometry and the values expressed in $\mathrm{mmHg}$. For these parameters values were obtained at time zero (T0), T30 (just after $30 \mathrm{~min}$ of ischemia) and T40 (beginning of reperfusion).

\section{Preparation of tissue extracts and homogenates}

All the oxidative stress parameters were evaluated in samples harvested from the both lungs using a small part of the lung parenchyma, the rest was stored in liquid nitrogen. The lung sample was carefully excised, surface-dried with filter paper, weighed and immediately stored in liquid nitrogen $\left(-170^{\circ} \mathrm{C}\right)$ until the different analyses. Lung homogenates (1:9 weight/volume) were obtained in a solution containing $0.1 \%$ Triton X-100, $0.12 \mathrm{M} \mathrm{NaCl}, 30 \mathrm{mM} \mathrm{Na}-$ phosphate buffer, $\mathrm{pH}$ 7.4. Homogenizations were carried out on ice $\left(4-5^{\circ} \mathrm{C}\right)$ using a tissue tearor during an interval of $10-15$ s, followed by centrifugation at $10,000 \mathrm{~g}$ for $10 \mathrm{~min}$. The supernatant was used for enzymatic assays. After tissue excision acid extracts were promptly prepared in $12 \%$ TCA (1:4, w:v) for the assays of glutathione and thiobarbituric acid-reactive substance (TBARS).

\section{Biochemical measurements}

\section{Antioxidant enzyme assays}

Catalase activity was determined by measuring the decrease of hydrogen peroxide in a freshly prepared $10 \mathrm{mM}$ solution at $240 \mathrm{~nm}$ [27]. Glutathione peroxidase was assayed at $340 \mathrm{~nm}$ according to Flohé and Gunzler through the glutathione/NADPH/glutathione reductase system, by the dismutation of tert-butylhydroperoxide [28]. All activities were measured in duplicate and expressed in grams of wet lung tissue.

\section{Glutathione assay}

Reduced glutathione (GSH) was measured in lung parenchyma according to Anderson [29] using the Elmann's reagent (DTNB: 2-dithionitrobenzoic acid). Immediately after the tissue excision, acid 
Silva FM (2017) Focusing lung transplant: physiological and antioxidant responses and effect of allopurinol to ischemia-reperfusion oxidative stress under different inspired oxygen concentrations

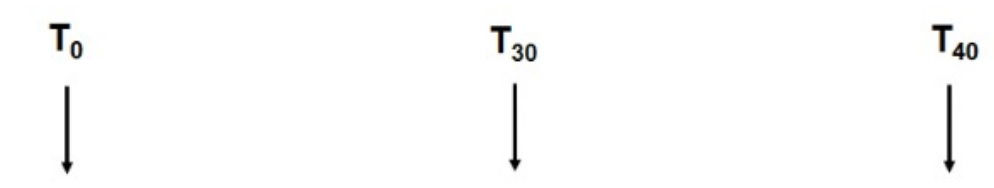

Without allopurinol

Ischemia Reperfusion

\begin{tabular}{|c|c|c|}
\hline \multicolumn{3}{|c|}{ WITHOUT ALLOPURINOL } \\
\hline GROUPS & \multicolumn{2}{|c|}{ ISCHEMIA } \\
\hline \multicolumn{3}{|l|}{ G1 } \\
\hline G2 & $\mathrm{O}_{2} 21 \%$ (normoxia) & $\mathrm{O}_{2} 21 \%$ (normoxia) \\
\hline G3 & $\mathrm{O}_{2} 100 \%$ (hyperoxia) & $\mathrm{O}_{2} 100 \%$ (hyperoxia) \\
\hline
\end{tabular}

\begin{tabular}{|c|c|c|}
\hline \multicolumn{3}{|c|}{ WITH ALLOPURINOL } \\
\hline GROUPS & \multicolumn{2}{|c|}{ ISCHEMIA } \\
\hline \multicolumn{3}{|l|}{ G1A } \\
\hline G2A & $\mathrm{O}_{2} 21 \%$ (normoxia) & $\mathrm{O}_{2} 21 \%$ (normoxia) \\
\hline G3A & $\mathrm{O}_{2} 100 \%$ (hyperoxia) & $\mathrm{O}_{2} 100 \%$ (hyperoxia) \\
\hline
\end{tabular}

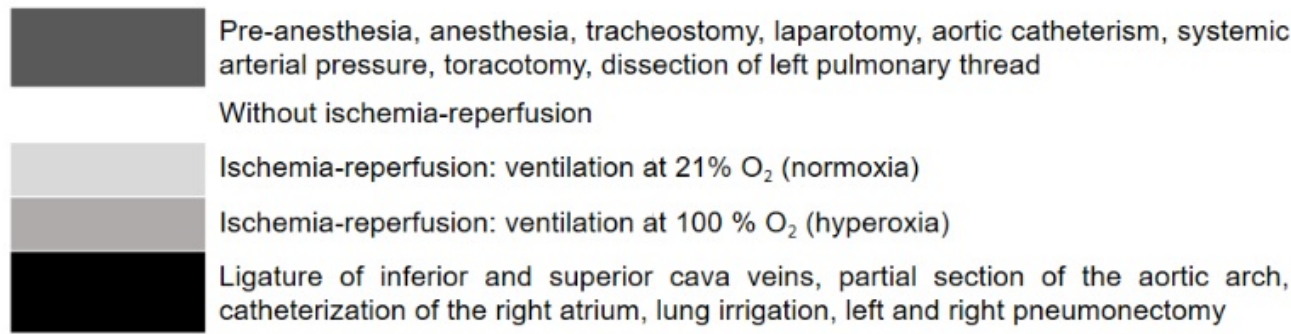

Figure 1. Flow sheet for cases

extracts were obtained by the addition of the $12 \%$ of trichloroacetic acid $(1: 4 \mathrm{v} / \mathrm{v})$, and vortexed for $30 \mathrm{~s}$, and centrifuged at 5,000 $\mathrm{g}$ for 10 min. Supernatants from the acid extracts were added with $0.25 \mathrm{mM}$ DTNB in $0.1 \mathrm{M} \mathrm{Na}$ phosphate, $\mathrm{pH} 8.0$, and the formation of thiolate anion was immediately determined at $412 \mathrm{~nm}(\varepsilon 412=14.1 \mathrm{M}-1 \mathrm{~cm}-1)$ during $3 \mathrm{~min}$. Samples were measured in duplicate and expressed in micromoles per gram of tissue.

\section{Lipid peroxidation assay}

Determination of thiobarbituric acid reactive substances (TBARS) was used for assessing endogenous lipid oxidation in lung parenchyma according to Ohkawa [30] and Bird and Draper [31]. Tissue acid extracts were obtained by the addition of the homogenate to trichloroacetic acid 12\%, vortexed and then centrifuged. Supernatants were centrifuged at $5,000 \mathrm{~g}$ for $5 \mathrm{~min}$, added with $0.67 \%$ (w/v) 2-thiobarbituric acid, maintained in boiling water for $60 \mathrm{~min}$, cooled at $5^{\circ} \mathrm{C}$ for $10 \mathrm{~min}$, and then measured spectrophotometrically at $535 \mathrm{~nm}$. Samples were measured in triplicate and expressed in nmol TBARS g tissue-1 using $\varepsilon_{535}=153 \mathrm{mM}^{-1} \mathrm{~cm}^{-1}$.

\section{Statistical analyses}

Multiple comparison test was performed by INSTAT software (GraphPad, San Diego, CA, USA), and data were analysed by ANOVA for non-parametric values by the Kruskal-Wallis test comparing each group with the others (G1 x G2 x G3), the same in those pretreated with allopurinol (G1A x G2A x G3A). When the initial comparison was significant by Kruskal-Wallis, data were complemented with the multiple comparison test of Mann-Whitney (G1 x G2; G1 x G3; G2 x $\mathrm{G} 3)$, the same with rats treated or not with allopurinol (G1A x G2A; G1A x G3A; G2A x G3A). Values were expressed as means \pm SEM, and $\mathrm{p}$-values less than $0.05(5 \%)$ were considered to be statistically significant.

\section{Results}

\section{Physiological parameters}

\section{Systemic arterial pressure (SAP)}

No significant differences were obtained for the systemic arterial pressure among the different groups at each time zero (time 0 ), when compared to each other using the Kruskal-Wallis test $(\mathrm{p}=0.3704)$. However, when comparing all the experimental period ( $0 \bigotimes 40$ minutes, i.e., after considering the whole IR experimental period), a significant difference was detected $\left(\mathrm{p}=0.0368^{*}\right.$; Kruskal-Wallis test; Table 1$)$. Using the complementary Mann-Whitney test, animals submitted to hyperoxia $(\mathrm{G} 3=100 \% \mathrm{FiO} 2)$ showed a decreased $\left(\mathrm{p}=0.0154^{\star}\right)$ systemic arterial pressure compared to controls (Sham), while no differences 
Silva FM (2017) Focusing lung transplant: physiological and antioxidant responses and effect of allopurinol to ischemia-reperfusion oxidative stress under different inspired oxygen concentrations

were detected for G2xG3 ( $\mathrm{p}=0.3845)$ and $\mathrm{G} 1 \mathrm{xG} 2(\mathrm{p}=0.0751)$ (Table 1$)$. Pretreatment with allopurinol (A) was able to decrease the systemic arterial pressure in all comparisons, i.e., normoxia conditions compared either to controls $\left(\mathrm{G} 1 \mathrm{xG} 2 \mathrm{~A} ; \mathrm{p}=0.0162^{*}\right)$, inside the normoxia group ( $\mathrm{G} 2 \mathrm{xG} 2 \mathrm{~A} ; \mathrm{p}=0.0033^{* *}$ ), as well as inside the hyperoxia group (G3xG3A; $p=0.0006^{* * *}$ ), considering the period of time $0 \rrbracket 40$ minute.

\section{Ratio $\mathrm{pO}_{2} / \mathrm{FiO}_{2}$}

The statistical analysis for the $\mathrm{pO} 2 / \mathrm{FiO} 2$ ratio under different ventilation conditions showed no differences among the groups at time zero ( $\mathrm{p}=0.5792$; Kruskal-Wallis test). However, when all the experimental period ( $0 \rightarrow 40$ minutes) was considered, a very significant difference was obtained $\left(\mathrm{p}=0.0001^{* * *}\right.$; Kruskal-Wallis test). Using the complementary Mann-Whitney test for the comparison among the three groups, and similar to the results found for the systemic arterial pressure, only the group submitted to hyperoxia ventilation showed a decreased ratio compared to rats ventilated under normoxia ventilation $\left(\mathrm{p}=0.0002^{\star * *}\right)$, as well as compared to controls $\left(p=0.0002^{* * *}\right)$, while the comparison between normoxia versus controls was not significant ( $\mathrm{p}=0.9397$; Table 1$)$.
When taken into consideration the effect of allopurinol pretreatment under different ventilation conditions again no significant differences among the groups at time zero were detected ( $\mathrm{p}=0.8824$; Kruskal-Wallis test). On the other hand, when considering experimental period of 40 minutes, all comparisons showed significant decreases of the $\mathrm{pO} 2 / \mathrm{FiO} 2$ ratio, at normoxic ventilation compared to controls (G1xG2A; $\left.\mathrm{p}=0.0162^{\star}\right)$, inside the normoxia group $\left(\mathrm{G} 2 \mathrm{xG} 2 \mathrm{~A} ; \mathrm{p}=0.0033^{*}\right)$, as well as inside the hyperoxia group $\left(G 3 x G 3 A ; p=0.0006^{\star * *}\right)($ Mann-Whitney test; Table 1$)$. Now, if the influence of allopurinol in IR (time $0 \rightarrow 40$ minutes) was compared in each group, the complementary Mann-Whitney test again showed a very significant difference only for rats exposed to hyperoxia ventilation $\left(\mathrm{G} 3 \times \mathrm{G} 3 \mathrm{~A} ; \mathrm{p}=0.0002^{\star * *}\right)$, while the antioxidant effect in the other groups was not significant for controls and ventilation under normoxia (G1xG1A; $=0.1733$; G2xG2A; $=0.4963$, respectively).

\section{Wet/dry weight ratio of the ischemic lung}

Using the Kruskal-Wallis test to compare the ratio between wet/ dry weight ratio in the left (ischemic) lung, a very significant difference $\left(p=0.0032^{\star *}\right)$ was detected when compared the different groups to each

Table 1. Systemic arterial pressure ( $\mathrm{SAP}$, in mmHg) and $\left(\mathrm{FiO}_{2}\right)$ in different experimental times $\left(\mathrm{t}_{0} \mathrm{t}_{30}\right.$ and $\left.\mathrm{t}_{40}\right)$ of controls (G1), lungs ventilated at normoxia (G2) or hyperoxia (G3), "A" after each group at the lower part of the table means animals pretreated with Allopurinol.

\begin{tabular}{|c|c|c|c|}
\hline Parameters & G1 & G2 & G3 \\
\hline $\mathrm{SAP}\left(\mathrm{t}_{0}\right)$ & $109.0 \pm 4.6$ & $117.8 \pm 3.4$ & $117.7 \pm 7.3$ \\
\hline $\operatorname{SAP}\left(t_{30}\right)$ & $112.2 \pm 8.2$ & $113.5 \pm 11.3$ & $103.3 \pm 9.7$ \\
\hline $\mathrm{SAP}\left(\mathrm{t}_{40}\right)$ & $106.1 \pm 12.8$ & $104.0 \pm 13.1$ & $98.3 \pm 15.1$ \\
\hline$\triangle \mathrm{SAP}$ & $-2.9 \pm 11.0$ & $-11.7 \pm 10.8$ & $-16.4 \pm 12.3$ \\
\hline$\Delta \mathrm{pO}_{2}$ & $29.7 \pm 34.4$ & $24.4 \pm 18.1 * * *$ & $-29.0 \pm 15.0 * * *$ \\
\hline $\mathrm{FiO}_{2}\left(\mathrm{t}_{0}\right)$ & $553.6 \pm 159.5$ & $579.0 \pm 90.4$ & $528.2 \pm 113.0$ \\
\hline $\mathrm{FiO}_{2}\left(\mathrm{t}_{30}\right)$ & $682.7 \pm 141.6$ & $736.9 \pm 97.2$ & $347.9 \pm 54.6$ \\
\hline $\mathrm{FiO}_{2}\left(\mathrm{t}_{40}\right)$ & $689.4 \pm 145.6$ & $712.1 \pm 97.8$ & $363.5 \pm 51.1$ \\
\hline Parameters & G1A & $\mathrm{G} 2 \mathrm{~A}$ & G3A \\
\hline $\operatorname{SAP}\left(\mathrm{t}_{0}\right)$ & $101.0 \pm 7.0$ & $110.5 \pm 8.0$ & $107.0 \pm 12.5$ \\
\hline $\operatorname{SAP}\left(\mathrm{t}_{30}\right)$ & $101.0 \pm 5.8$ & $104.5 \pm 12.1$ & $103.5 \pm 10.3$ \\
\hline $\mathrm{SAP}\left(\mathrm{t}_{40}\right)$ & $103.7 \pm 7.8$ & $104.5 \pm 8.6$ & $104.5 \pm 10.4$ \\
\hline$\triangle \mathrm{SAP}$ & $2.2 \pm 7.7^{*}$ & $-5.4 \pm 4.6^{* *}$ & $-1.8 \pm 8.9^{* * *}$ \\
\hline$\Delta \mathrm{pO}_{2}$ & $11.7 \pm 12.1$ & $21.5 \pm 30.7$ & $12.6 \pm 7.8^{* * *}$ \\
\hline $\mathrm{FiO}_{2}\left(\mathrm{t}_{0}\right)$ & $588.9 \pm 118.0$ & $553.5 \pm 155.2$ & $548.7 \pm 46.8$ \\
\hline $\mathrm{FiO}_{2}\left(\mathrm{t}_{30}\right)$ & $661.9 \pm 106.6$ & $640.4 \pm 120.4$ & $504.0 \pm 42.5$ \\
\hline $\mathrm{FiO}_{2}\left(\mathrm{t}_{40}\right)$ & $650.4 \pm 104.4$ & $635.2 \pm 81.9$ & $476.6 \pm 24.0$ \\
\hline
\end{tabular}

Significant differences applying Kruskall-Wallis test followed by the complementary Mann-Whitney test according to the experimental period form $T_{0} \rightarrow T_{40}: \Delta$ SAP: G1A* $\mathrm{x}$ G1, G2A* $\mathrm{x}$

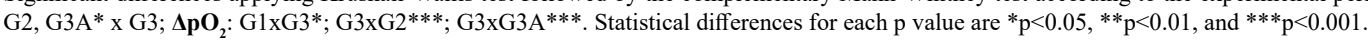

Table 2. Biomarkers of oxidative stress in lung tissue of controls (G1), lungs ventilated at normoxia (G2) or hyperoxia (G3). "A" after each group at the lower part of the table means animals pretreated with Allopurinol. Activity of CAT (catalase; mmol min ${ }^{-1} \mathrm{~g}_{\text {wet tissue }}^{-1}$ ), GPx (glutathione peroxidase; $\mu \mathrm{mol} \mathrm{min}^{-1} \mathrm{~g}^{-1}$ ), contents of GSH (reduced glutathione; mol g-1) and TBARS (lipoperoxidation; nmol TBARS g-1).

\begin{tabular}{|c|c|c|c|c|c|c|}
\hline \multirow{2}{*}{ Markers } & \multicolumn{2}{|c|}{ G1 (controls) } & \multicolumn{2}{|c|}{ G2 (normoxia) } & \multicolumn{2}{|c|}{ G3 (hyperoxia) } \\
\hline & Left & Right & Left & Right & Left & Right \\
\hline CAT & $0.94 \pm 0.34$ & $1.01 \pm 0.38$ & $1.14 \pm 0.40$ & $1.46 \pm 0.63$ & $0.75 \pm 0.26$ & $0.76 \pm 0.27^{\beta}$ \\
\hline GPx & $453.4 \pm 105.7$ & $343.2 \pm 54.56$ & $512.1 \pm 161.4$ & $448.8 \pm 109.4$ & $443.5 \pm 73.2$ & $418.5 \pm 135.1$ \\
\hline GSH & $0.97 \pm 0.38$ & $1.13 \pm 0.31$ & $1.03 \pm 0.28$ & $1.28 \pm 0.26$ & $0.62 \pm 0.15^{\alpha \beta}$ & $1.12 \pm 0.22$ \\
\hline TBARS & $50.21 \pm 38.13$ & $40.30 \pm 39.33$ & $59.32 \pm 38.34$ & $59.52 \pm 38.95$ & $80.64 \pm 35.65$ & $65.70 \pm 31.94$ \\
\hline \multirow{2}{*}{ Markers } & \multicolumn{2}{|c|}{ G1A } & \multicolumn{2}{|c|}{ G2A } & \multicolumn{2}{|c|}{ G3A } \\
\hline & Left & Right & Left & Right & Left & Right \\
\hline CAT & $0.35 \pm 0.40^{\gamma}$ & $0.67 \pm 0.81$ & $0.55 \pm 0.33^{\delta}$ & $0.60 \pm 0.33^{\delta}$ & $0.19 \pm 0.10^{\varepsilon}$ & $0.34 \pm 0.26^{\xi}$ \\
\hline GPx & $266.2 \pm 100.8^{\gamma}$ & $269.3 \pm 67.5$ & $189.7 \pm 39.7^{\xi \delta}$ & $234.5 \pm 46.9$ & $267.4 \pm 77.0^{\varepsilon}$ & $301.4 \pm 53.1^{\xi}$ \\
\hline GSH & $1.13 \pm 0.13$ & $1.24 \pm 0.43$ & $0.89 \pm 0.22$ & $1.34 \pm 0.25$ & $0.84 \pm 0.25^{\AA}$ & $1.27 \pm 0.20$ \\
\hline TBARS & $52.11 \pm 22.41$ & $62.23 \pm 9.60^{\gamma}$ & $61.21 \pm 23.80$ & $79.20 \pm 50.34$ & $44.43 \pm 12.93^{\varepsilon}$ & $59.53 \pm 32.12^{\varepsilon}$ \\
\hline
\end{tabular}

Different superscript letters denote significant differences applying Kruskall-Wallis test followed by the complementary Mann-Whitney test according to: $(\alpha)$ between G1xG3; $(\beta)$ between G2xG3; $(\gamma)$ between G1xG1A; $(\delta)$ between G2xG2A; $(\varepsilon)$ between G3xG3A; $(£)$ between G1A x G3A; $(\xi)$ between G2AxG3A. Specific values for each $p(p<0.05$, p $<0.01$, or $p<0.001)$ can be found in the Result section. 
other. However, when considering the entire experimental period $(0 \rightarrow$ 40 minutes) corresponding to the IR experimental period, a significant difference was also detected for the ischemic lung ( $\mathrm{p}=0.0368^{*}$; KruskalWallis test; Table 1). Using the complementary Mann-Whitney test, animals submitted to hyperoxia $(\mathrm{G} 3=100 \% \mathrm{FiO} 2)$ showed a decreased ratio compared either to controls (G1 vs. $\mathrm{G} 3 ; \mathrm{p}=0.0017^{* *}$ ) or to normoxia exposed lungs (G2 vs. G3; $\mathrm{p}=0.0010^{* * *}$ ) (Table 1). On the other hand, pretreatment with allopurinol compared to rats not pretreated with the antioxidant, was able to decrease the ratio in all comparisons, showing very significant differences. More specifically, comparing the effect of allopurinol inside the control group (G1xG1A; $\left.\mathrm{p}=0.0003^{* * *}\right)$, inside the normoxia group $\left(\mathrm{G} 2 \mathrm{xG} 2 \mathrm{~A} ; \mathrm{p}=0.0015^{\star *}\right)$, as well as inside the hyperoxia group (G3xG3A; $\left.\mathrm{p}=0.0002^{\star * *}\right)$, in all of them the antioxidant treatment was very effective in decreasing the oxidative insult in the ischemic lungs.

\section{Marker of OS - Lipoperoxidation levels (TBARS)}

In the present study TBARS contents in lung parenchyma showed only a tendency to increase under ventilation not protected with allopurionl, however this tendency showed a relationship with the higher $\mathrm{FiO}_{2}$. The values found after the Kruskal-Wallis test detected not significant values between the different groups, neither for the left ischemic lung $(\mathrm{p}=0.2117)$ nor for the right lung $(\mathrm{p}=0.1852)$. Considering the effect of allopurinol comparing both lungs under different ventilation conditions, values for the left lung $(\mathrm{p}=0.1814)$ and right lung $(\mathrm{p}=0.7783)$ showed no statistical significance among the three groups after applying the complementary Mann-Whitney test (Table 2). However, when the effect of allopurinol was compared with animals not previously treated with this antioxidant after applying the Mann-Whitney test significant differences were detected, either for the ischemic lung exposed to hyperoxia ( $G 3$ vs. $G 3 A ; p=0.0188^{\star}$ ), as well for the right lung in animals of the control group (G1 vs. G1A; $\left.\mathrm{p}=0.0306^{\star}\right)($ Table 2$)$. The other comparisons were not significant for the left lung (G1 vs. G1A; $\mathrm{p}=0.6498 ; \mathrm{G} 2$ vs. G2A; $\mathrm{p}=0.9397$ ) and also for the right lung (G2 vs. G2A; p=0.5960; G3 vs. G3A; $\mathrm{p}=0.6217$ ) (Table 2).

\section{Antioxidants - GSH}

The effect of ventilation at different oxygen tensions and also considering the effect of allopurinol in both lungs on the responses of GSH in lung parenchyma revealed only significant differences for the left ischemic lung using the Kruskal-Wallis test $\left(\mathrm{p}=0.0062^{\star}\right)$, while for the right lung no difference was obtained ( $\mathrm{p}=0.3362$; Table 2$)$. Significant differences were also detected applying the complementary Mann-Whitney test between different ventilations in the left lungs ventilated under hyperoxia either comparing with normoxia (G2 vs. $\mathrm{G} 3 ; \mathrm{p}=0.0009^{* * *}$ ) or comparing with controls (G1 vs. G3; $\mathrm{p}=0.0375^{\star}$ ) (Table 2), while the comparison between G1 vs. $\mathrm{G} 2(\mathrm{p}=0.8798)$ was not significant.

When considering the effect of allopurinol, the Kruskal-Wallis test detected a significant difference for the ischemic lung $\left(\mathrm{p}=0.0505^{\star}\right)$, but not for the right lung $(\mathrm{p}=0.6921)$. The statistical analysis inside each group revealed significant differences for ventilation at normoxia compared to controls $\left(\mathrm{G} 1 \mathrm{AxG} 2 \mathrm{~A} ; \mathrm{p}=0.0310^{\star}\right)$ and ventilation at hyperoxia compared to controls $\left(\mathrm{G} 1 \mathrm{AxG} 3 \mathrm{~A} ; \mathrm{p}=0.0315^{\star}\right)$, while no significant difference appeared between the effect of allopurinol comparing normoxia and hyperoxia ventilation (G2AxG3A; $p=0.7620$; Mann-Whitney test; Table 2).

\section{Antioxidant Enzymes (GPx):}

Using the Kruskal-Wallis test for glutathione peroxidase activity in lung parenchyma no significant differences were detected either for the ischemic lung ( $\mathrm{p}=0.9658)$, or for the right lung $(\mathrm{p}=0.0748)$, for animals not pretreated with allopurinol (Table 2). However, pretreatment with allopurinol gave significances when comparing both lungs each other or with controls by the Kruskal-Wallis test, for the left ischemic lung $\left(\mathrm{p}=0.0535^{\star}\right)$, as well as for the right lung $\left(\mathrm{p}=0.0408^{\star}\right)$. After applying the Mann-Whitney test (Table 2) pretreatment with allopurinol, the ischemic lung showed significant difference comparing G1A vs. G2A $\left(\mathrm{p}=0.0343^{\star}\right), \mathrm{G} 2 \mathrm{~A}$ vs. G3A $\left(\mathrm{p}=0.0413^{\star}\right)$, while the left lung ventilated under hyperoxia and compared to controls revealed no significant difference $(p=0.9698)$. For the non-ischemic right lung no significant statistical results were obtained for the two ventilations compared to controls (G1A vs. G2A; p=0.1124 and G1A vs. G3A; $p=0.3445$ ), while the comparison for normoxia versus hyperoxia ventilation revealed a significant difference $\left(\mathrm{G} 2 \mathrm{~A}\right.$ vs. G3A, $\left.\mathrm{p}=0.0140^{\star}\right)$. Furthermore, when the mean values of rats ventilated with and without pretreatment with allopurinol were compared, significant differences appeared in all three groups for both lungs by the Mann-Whitney test (Table 2). For the ischemic lung the following results were obtained: G1 vs. G2A $\left(p=0.0156^{\star}\right), G 2$ vs. G2A $\left(p=0.0005^{\star * *}\right), G 3$ vs. G3A $\left(0.0007^{\star * *}\right)$. For the non-ischemic lung: G1 vs. G2A $\left(\mathrm{p}=0.0233^{\star}\right), \mathrm{G} 2$ vs. G2A $\left(\mathrm{p}=0.0003^{* * *}\right), \mathrm{G} 3$ vs. G3A $\left(0.0222^{\star}\right)$.

\section{Antioxidant Enzymes (CAT):}

Surprisingly and contrary to the other results obtained regarding OS markers, catalase activity showed no significant differences in the ischemic lung $(\mathrm{p}=0.0800)$, while for the right lung $\left(\mathrm{p}=0.0396^{*}\right)$ a significant difference was detected using the Kruskal-Wallis test (Table 2). The complementary Mann-Whitney test revealed a significant difference $\left(\mathrm{p}=0.0284^{*}\right)$ comparing CAT values for the right lung (G2 vs. G3; Table 2). The pretreatment with allopurinol showed significances only for the ischemic left lung $\left(\mathrm{p}=0.0399^{\star}\right)$ when comparing both lungs through the Kruskal-Wallis test (Table 2). Similar to the response obtained for GPx, after applying the MannWhitney test, a significant difference $\left(\mathrm{p}=0.0101^{*}\right)$ was detected for the left lung, comparing inside each group under distinct ventilation conditions in animals treated with allopurinol (G2A vs. G3A; Table 2). On the other hand, when comparing animals treated and non-treated with allopurinol, the right lung showed no significant differences between controls G1xG1A ( $\mathrm{p}=0.0695)$, while the comparison between G2xG2A $\left(\mathrm{p}=0.0052^{\star *}\right)$ and G3xG3A $\left(\mathrm{p}=0.0065^{\star *}\right)$, such comparison were very significant (Table 2). The left ischemic lung showed significant differences in all three groups by the Mann-Whitney test (Table 2), when comparing G1 vs. G1A ( $\left.\mathrm{p}=0.0041^{\star *}\right), \mathrm{G} 2$ vs. G2A $\left(\mathrm{p}=0.0082^{\star \star}\right)$, and G3 vs. G3A $\left(\mathrm{p}=0.0003^{\star \star \star}\right)$ (Table 2$)$

\section{Discussion}

\section{Physiological parameters}

Pretreatment with allopurinol decreased the systemic arterial pressure while preserving the $\mathrm{pO}_{2} / \mathrm{FiO}_{2}$ ratio comparing to controls (Table 1), demonstrating its beneficial physiological property. Similar finding was obtained by Zhao and collaborators [19] in rat lung. Allopurinol in fact is effective in decreasing the edema and/or OS related to IR in different organs [19,21-25]. Furthermore, the ratio wet/ dry lung weight reflects the secundary edema to IR injury in different studies, and the very significant difference obtained for this parameter evaluated in the present study $\left(0,0032^{\star}\right)$ is in accordance to other similar studies. Furthermore, we have also measured the $\mathrm{pO} 2 / \mathrm{FiO} 2$ ratio, which is considered an indirect evaluation of the endothelium disfunction. Lung edema is related to higher capillary permeability due to endothelium disfunction, which in turn is related to ATP 
Silva FM (2017) Focusing lung transplant: physiological and antioxidant responses and effect of allopurinol to ischemia-reperfusion oxidative stress under different inspired oxygen concentrations

decrease, as well as to the release of several inflammatory mediators and also to high ROS overproduction [32]. Accordingly, in our study the group submitted to hyperoxia showed a decreased value for this ratio, thus inferring the damage related to capillary permeability.

Considering that only the animals submitted to hyperoxia ( $\mathrm{G} 3=100 \% \mathrm{FiO} 2)$ showed a decrease in the systemic arterial pressure when compared to controls (Sham operation) as well as those exposed to normoxia, probably indicating that the lung tissue was damaged by ROS overgeneration when high partial pressures of oxygen are present. This result is in accord to Haniuda and collaborators [33], who also detected enhanced lipoperoxidation levels in lungs preserved at moderate hypothermia. In addition and similar to the results found for the systemic arterial pressure, the $\mathrm{pO} 2 / \mathrm{FiO} 2$ ratio showed a decreased ratio compared to normoxia (G2) and the control group (G1). This suggest that under high oxygen concentration the alveolar/ capillary membrane integrity was probably jeopardized [34], which is in accord to other related studies $[4,33,35,36]$. It is also important to stress out that lung function after transplant can be also improved by a relatively slow increase in both ventilation rate as well as in blood flow during reperfusion [37].

\section{Marker of OS - Lipoperoxidation levels (TBARS)}

In the present study TBARS contents in lung tissue showed only a tendency to increase under ventilation not protected with allopurinol, however this tendency showed a relationship with the higher $\mathrm{FiO}_{2}$. This response is similar to those found in related studies involving lung IR injury [33,38,39], the former authors also described a similar damage to proteins through protein carbonyl levels [39]. Accordingly, when ventilation of lungs not pretreated with allopurinol was compared, higher TBARS levels were detected in the hyperoxia group, in other words, the previous treatment with this antioxidant was able to decrease OS damage in the ischemic lung. Fisher and collaborators [8] also showed a protective effect of allopurinol decreasing levels of lipoperoxidation during IR in rats. Furthermore, such protection against lipid damage was also demonstrated in rats through a preservation solution containing allopurinol [40].

Allopurinol is analogous to hypoxanthine, thereby acting as a xanthine oxidase inhibitor and leading to a lower generation of superoxide anion [14]. In this sense oxipurinol, the major metabolite derived from allopurinol, is a very efficient scavenger of the deleterious hydroxil radical $(\bullet \mathrm{OH})$ [41], which is the main ROS responsible for damaging cellular and organelle membranes [14]. Lipoperoxidation is the oxidation of unsaturated lipids and cholesterol in membranes as well as in lipoproteins, which is promoted by ROS [14]. This lipid oxidation process is considered the most widespread and deleterious consequence of IR in different organs and tissues [41-46].

It is worth to stress out that measurements of lipoperoxidatin as TBARS, as well as other markers of oxidative insult, are often used for the evaluation of tissue lesion associated to IR injury [5,19,26,4446]. Furthermore, in the spectrophotometric TBARS assay, malondialdehyde (MDA) is the major (approximately 90\%) among other toxic dialdehydes produced by lipid oxidation especially on cell membranes [14].

\section{Antioxidants - GSH}

Compared to controls, a progressive depletion of GSH contents in the ischemic lung tissue was revealed, both under normoxia and hyperoxia (21\% and $100 \% \mathrm{FiO}_{2}$, respectively), clearly indicating that hyperbaric ventilation jeopardized the glutathione protection. GSH is a widespread endogenous and generalist antioxidant [14], being very effective in quenching of ROS and RNS. In this sense, ${ }^{\mathrm{NO}}$ is toxic only in the early stages of reperfusion because of its interaction with superoxide anion $\left(\mathrm{O} 2^{*}\right)$, thus forming the very reactive and deleterious peroxinitrate (ONOO-) [14].

In the present study a significant difference in GSH concentrations in tissue lung was also obtained between hyperoxia and normoxia ventilations. Such response is probably reflecting the higher ROS generation related to hyperoxia ventilation, GSH being depleted to compensate and attenuating OS in lung tissue. Depletion of reduced glutathione concentrations in severe OS conditions is critical for cell homestasis [14]. Such OS condition and GSH depletion were present in patients with bronchiolitis obliterans syndrome (BOS), which is considered the most serious long-term sequel of lung and heart-lung transplantation [47].

As a matter of fact, OS and GSH depletion is always detected in patients undergoing organ transplantation [48], GSH levels being rapidly decreased while producing high levels of its oxidized form (GSSG), which is very toxic to cells and tissues [14]. In this regard, GSH present in a preservation fluid prevents pulmonary edema following lung transplantation in dogs [45]. In the present study pretreatment with allopurinol was also able to prevent GSH depletion associated with hyperoxia ventilation, confirming the high antioxidant capacity of this ubiquitous tripeptide, which is present in all tissues of aerobic organisms approximately in $\mathrm{mM}$ concentrations $[11,12,14]$. As already mentioned above, allopurinol and its major metabolite oxypurinol are both excellent scavengers of ${ }^{\circ} \mathrm{OH}$ (hydroxyl radical), considered the most deleterious ROS [41].

\section{Antioxidant Enzymes}

No significant differences were detected in the three groups examined for the two antioxidant enzymes evaluated in rats submitted to IR and not pretreated with allopurinol. The same result was described by Bryan and collaborators [45]. On the other hand, when ventilation of lungs not pretreated with allopurinol was compared to rats protected with the pretreatment of allopurinol, both enzymes were downregulated, probably accompanying the decrease of hydrogen peroxide concentrations promoted by allopurinol. GPx and CAT are the two main antioxidant enzymes present in the intracellular environment responsible for hydrogen peroxide detoxification into water and oxygen [14]. Thus ROS, especially considering hydrogen peroxide and other peroxides, such as those generated through the lipoperoxidation processes produced by IR, induced GPx and CAT activity to compensate the associated OS [49]. It is well known that higher cell concentrations of $\mathrm{H}_{2} \mathrm{O}_{2}$ produces the hydroxyl radical via the Fenton reaction catalyzed by transition metals, or via the HaberWeiss reaction, when combined with superoxide anion (O2*) [14]. In this regard, significant iron-generated OS was already demonstrated in lung transplantation, which might be exacerbated by nitric oxide $(\cdot \mathrm{NO})$, particularly in BOS [50].

Also, as previously mentioned, the antioxidant allopurinol is able to decrease OS damage in the ischemic lung, thereby decreasing the ratio wet/dry lung weight, which reflects the lung edema [19,25]. Furthermore, in the present study the $\mathrm{pO}_{2} / \mathrm{FiO}_{2}$ ratio was decreased in rat lungs submitted to hyperoxia, similar to the results described in other related studies $[5,32]$. In summary, all the physiological responses seem to be closely associated with the antioxidant responses, 
Silva FM (2017) Focusing lung transplant: physiological and antioxidant responses and effect of allopurinol to ischemia-reperfusion oxidative stress under different inspired oxygen concentrations

probably acting in a concerted manner to compensate tissue and cellular damage following lung IR process.

Accordingly, the pretreatment with vitamin $\mathrm{C}$ was also able to attenuate lung injury after ischemia (3h)-reperfusion (1h) in rat heart, which also showed decreased plasma leukocyte sequestration [51]. Furthermore, in vivo experiments in pigs showed that chemiluminescence measurements in animals previously supplemented with vitamins $\mathrm{C}$ and $\mathrm{E}$ were able to attenuate the injury associated to ischemia followed by reperfusion [2], as well as CAT immunotargeting to the pulmonary endothelium was also able to decrease IR injury [52]. Several other antioxidant supplementation studies were also effective to demonstrate the beneficial effect of such interventions in lowering OS associated with IR in different organs and tissues [3,5,7,14,21-26].

Nitric oxide $(\cdot \mathrm{NO})$ also plays an important role in OS related to IR in different organs [14]. In this regard, ${ }^{-N O}$ seems to be toxic only in the early stages of reperfusion because of its interaction with superoxide anion $\left(\mathrm{O} 2^{*}\right)$, thereby forming a non-radical species peroxinitrate (ONOO-), which is a very deleterious and diffusible RNS [14]. Interestingly and corroborating the general results obtained in the present study under ventilation at $0.21 \mathrm{~atm} \mathrm{FiO}_{2}$, only at normoxic condition the inhalation of ' $\mathrm{NO}$ during lung ventilation was able to promote a significant and pronounced decrease in the mean pulmonary pressure of transplanted lungs in pigs [53].

At last and not least, it is interesting to realize that IR process is a physiological and normal physiological routine sustained by some animals, especially in diving mammals, in such a way enabling them to overcome the systemic oxidative stress related to IR [53]. Not surprisingly, these organisms possess a constitutive and relatively high antioxidant system in blood and in different organs to continuously compensate the IR insult associated with alternated surface breathing and long apnea-related ischemic periods of diving compared to nondiving mammals $[12,54]$.

\section{Conclusions}

The IR process in lungs using ventilation at normoxia $\left(0.21 \mathrm{pO}_{2}\right)$ compared to hyperbaric ventilation $\left(1.00 \mathrm{pO}_{2}\right)$ showed decreased systemic arterial pressure (SAP), higher $\mathrm{PaO}_{2} / \mathrm{FiO}_{2}$ ratio and wet/dry weight ratio in the ischemic lung, lower pulmonary edema, as well as attenuated lung tissue damage associated to the OS markers. In addition, pretreatment with allopurinol was able to generally improve the parameters here examined. Therefore, ventilation under normoxia and use of allopurinol is recommended for lung transplantation and organ preservation to attenuate the associated OS ischemiareperfusion injury in lung parenchyma.

\section{Acknowledgements}

DWF thanks the Research Fellowship from the Brazilian agency CNPq, Brazil (Proc. 303234/2015-6).

\section{References}

1. Ambrosio G, Tritto I (1999) Reperfusion injury: experimental evidence and clinical implications. Amer Heart J 138: S69-S75. [Crossref]

2. Wagner FM, Weber AT, Ploetze K, Schubert F, Pfeiffer S et al. (2002) Do vitamins C and $\mathrm{E}$ attenuate the effects of reactive oxygen species during pulmonary reperfusion and thereby prevent injury? Ann Thorac Surg 74: 811-817. [Crossref]

3. Madill J, Aghdassi E, Arendt B, Hartman CB, Gutierrez C, et al. (2009) Lung transplantation: does oxidative stress contribute to the development of bronchiolitis obliterans syndrome? Transplantation Reviews 23: 103-110. [Crossref]
4. Fard N, Arash S, Emami G, Hofer S, Kauczor HU, et al. (2014) Acute respiratory distress syndrome induction by pulmonary ischemia-reperfusion injury in large animal models. J Surg Res 189: 274-284. [Crossref]

5. Ferrari RS, Andrade CF (2015) Oxidative Stress and Lung Ischemia-Reperfusion Injury. Oxidative Medicine and Cellular Longevity $\mathrm{pp}: 1-14$.

6. Grace PA (1994) Ischaemia-reperfusion injury. Br J Surg 81: 637-647. [Crossref]

7. Omar B, McCord J (1991) Ischemia-reperfusion. In: H. Sies, ed. Oxidative stress Oxidants and antioxidants. Academic Press. London: 493-527.

8. Fisher AB, Dodia C, Tan ZT, Ayene I, Eckenhoff RG (1991) Oxygen-dependent lipid peroxidation during lung ischemia. J Clin Invest 88: 674-679. [Crossref]

9. Eiserich JP, Patel RP, O’Donnell VB (1998) Pathophysiology of nitric oxide and related species: free radical reactions and modification of biomolecules. Mol Aspects Med 19: 221-357. [Crossref]

10. Zar, H.A., Tanigawa, K., Young-Myeong, K., Lancaster Jr., J.R., (1998) Rat liver postischemic lipid peroxidation and vasoconstriction depend on ischemia time. Free Radic Biol Med 25: 255-264. [Crossref]

11. Wilhelm Filho D, Torres MA, Bordin ALB, Crezcynski-Pasa TB, Boveris A (2004) Spermatic cord torsion, reactive oxygen and nitrogen species and ischemia-reperfusion injury. Mol Aspects Medic 25: 199-210. [Crossref]

12. Righetti BPH, Simões Lopes P, Wilhelm Filho D (2014) Relating diving behavior and antioxidant status: insights from oxidative stress biomarkers in the blood of two distinct divers, Mirounga leonina and Arctocephalus australis. Comp Biochem Physiol Part A, Mol Integr Physiol 45: 34-39. [Crossref]

13. Weiss SJ (1986) Oxygen, ischemia and inflammation. Acta Physiol Scand Suppl 548 9-37. [Crossref]

14. Halliwell B, Gutteridge JMC (2007) Free Radicals in Biology and Medicine. 4th ed. Oxford Univ. Press, London.

15. Adkins WK, Taylor AE (1990) Role of xanthine oxidase and neutrophils in ischemiareperfusion injury in rabbit lung. $J$ Appl Physiol (1985) 69: 2012-2018. [Crossref]

16. Parks DA, Bulkley GB, Granger DN, Hamilton SR, McCord JM (1982) Ischemic injury in the cat small intestine: role of superoxide radicals. Gastroentorology 82: 9-15. [Crossref]

17. McCord JM (1985) Oxygen-derived free radicals in postischemic tissue injury. $N$ Engl $J$ Med 312: 159-163. [Crossref]

18. González-Flecha BS, Cutrin J, Boveris A (1993) Time course and mechanism of oxidative stress and tissue damage in rat liver subjected to in vivo ischemia-reperfusion. J Clin Invest 91: 456-464. [Crossref]

19. Zhao G, Al-MehdiI AB, Fisher AB (1997) Anoxia-reoxygenation versus ischemia in isolated rat lungs. Am J Physiol 273: L1112-7. [Crossref]

20. Cutrin JC, Boveris A, Zingaro B, Corvetti G, Poli G (2000) In situ determination by surface chemiluminescence of temporal relationships between evolving warm ischemia-reperfusion injury in rat liver and phagocyte activation and recruitment. Hepatology 31: 622-632. [Crossref]

21. Godin DV, Bhimji S (1987) Effects of allopurinol on myocardial ischemic injury induced by coronary artery ligation and reperfusion. Biochem Pharmacol 36: 21012107. [Crossref]

22. Bonser RS, Fragomeni LS, Edwards BJ, Goldston E, Fischel R, et al. (1990) Allopurinol and deferoxamine improve canine lung preservation. Transplant Proc 22: 557-558. [Crossref]

23. Cohen PJ (1992) Allopurinol administered prior to hepatic ischaemia in the rat prevents chemiluminescence following restoration of circulation. Can J Anaesth 39:1090-1093. [Crossref]

24. Vaughan WG, Horton JW, Walker PB (1992) Allopurinol prevents intestinal permeability changes after ischemia-reperfusion injury J Pediatr Surg 27: 968-972. [Crossref]

25. Okuda M, Furuhashi K, Nakai Y, Muneyuki M (1993) Decrease of ischaemiareperfusion related lung oedema by continuous ventilation and allopurinol in rat perfusion lung model. Scand J Clin Lab Invest 53: 625-631. [Crossref]

26. Rhoden E, Teloken C, Lucas M, Rhoden C, Mauri M, et al. (2000) Protective effect of allopurinol in the renal ischemia--reperfusion in uninephrectomized rats. Gen Pharmacol 35:189-193. [Crossref]

27. Aebi H (1984) Catalase in vitro. Methods Enzymol 105: 121-126. [Crossref] 
Silva FM (2017) Focusing lung transplant: physiological and antioxidant responses and effect of allopurinol to ischemia-reperfusion oxidative stress under different inspired oxygen concentrations

28. Flohé L, Günzler WA (1984) Assays of glutathione peroxidase. Methods Enzymol 105: 114-121. [Crossref]

29. Anderson MA (1985) Determination of glutathione and glutathione disulfide in biological samples. Methods Enzymol 113: 548-555. [Crossref]

30. Ohkawa H, Ohishi N, Yagi K (1979) Assay for lipid peroxides in animal tissues by thiobarbituric acid reaction. Anal Biochem 95: 351-358. [Crossref]

31. Bird RP, Draper AH (1984) Comparative studies on different methods of malondyhaldehyde determination. Methods Enzymol 90: 105-110. [Crossref]

32. Eppinger MJ, Deeb GM, Bolling SF, Ward PA (1997) Mediators of ischemia-reperfusion injury of rat lung. Am J Pathol 150: 1773-1784. [Crossref]

33. Haniuda M, Dresler CM, Mizuta T, Cooper JD, Patterson GA.(1995) Free radicalmediated vascular injury in lungs preserved at moderate hypothermia. Ann Thorac Surg 60: 1376-1381. [Crossref]

34. Novick RJ, Gehman KE, Ali IS, Lee J (1996) Lung preservation: the importance of endothelial and alveolar type II cell integrity. Ann Thorac Surg 62: 302-314. [Crossref]

35. Kirk AJ, Colquhoun IW, Dark JH (1993) Lung preservation: a review of current practice and future directions. Ann Thorac Surg 56: 990-100. [Crossref]

36. Kiser AC, Ciriaco P, Hoffmann SC, Egan TM (2001) Lung retrieval from non-heart beating cadavers with the use of a rat lung transplant model. J Thorac Cardiovasc Surg 122: 18-23. [Crossref]

37. Singh RR, Laubach VE, Ellman PI, Reece TB, Unger E, et al. (2006) Attenuation of lung reperfusion injury by modified ventilation and reperfusion techniques. $J$ Heart Lung Transplant 25: 1467-1473. [Crossref]

38. Marotto ME, Thurman RG, Lemasters JJ (1989) Early midzonal cell death during lowflow hypoxia in the isolated, perfused rat liver: protection by allopurinol. Hepatology 8: $585-590$.

39. Ayene IS, Dodia C, Fisher AB (1992) Role of oxygen in oxidation of lipid and protein during ischemia/reperfusion in isolated perfused rat lung. Arch Biochem Biophys 296: 183-189. [Crossref]

40. Nezu K, Kushibe K, Tojo T, Sawabata N, Kawachi K, et al. (1994) Protection against lipid peroxidation induced during preservation of lungs for transplantation. J Heart Lung Transplant 13: 998-1002.

41. Moorhouse PC, Grootveld M, Halliwell B, Quinlan JG, Gutteridge JM (1987) Allopurinol and oxypurinol are hydroxyl radical scavengers. FEBS Lett 213: 23-28. [Crossref]
42. Joannidis M, Gunther B, Pfäller W (1989) Lipid-peroxidation: an initial event in experimental acute renal failure. Ren Physiol Biochem 12: 47-55. [Crossref]

43. Poli G, Cutrin JC, Biasi F (1998) Lipid peroxidation in the reperfusion injury of the liver. Free Radic Res 28: 547-551. [Crossref]

44. Waintrub ML, Terada LS, Beehler CJ, Anderson BO, Leff JA, et al. (1990) Xanthine oxidase is increased and contributes to paraquat-induced acute lung injury. $J \mathrm{Appl}$ Physiol (1985) 68: 1755-1757. [Crossref]

45. Bryan, CL, Cohen DJ, Dew JA, Trinkle JK, Jenkinson SG (1991) Glutathione decreases the pulmonary reimplantation response in canine lung autotransplants. Chest 100 1694-1702. [Crossref]

46. Stammberger U, Schmid RA, Hillinger S, Singer T, Schob OM, et al. (1998) Effect of a short period of warm ischemia after cold preservation on reperfusion injury in lung allotransplantation. Eur J Cardiothorac Surg 13:442-447. [Crossref]

47. Behr J, Maier K, Braun B, Schwaiblmair M, Vogelmeier C. (2000). Evidence for oxidative stress in bronchiolitis obliterans syndrome after lung and heart-lung transplantation. Transplantation 69(9): 1856-1860.

48. Inal M, AltiniÅŸik M, Bilgin MD (2002) The effect of quercetin on renal ischemia and reperfusion injury in the rat. Cell Biochem Funct 20: 291-296. [Crossref]

49. Ho YS, Dey MS, Crapo JD (1996) Antioxidant enzyme expression in rat lungs during hyperoxia. Am J Physiol 270: L810-818. [Crossref]

50. Reid D, Snell G, Ward C, Krishnaswamy R, Ward R, et al. (2001) Iron overload and nitric oxide-derived oxidative stress following lung transplantation. $J$ Heart Lung Transplant 20: 840-849. [Crossref]

51. Baltalarli A, Ozcan V, Bir F, Aybek H, Sacar M, et al. (2006) Ascorbic acid (vitamin C) and iloprost attenuate the lung injury caused by ischemia/reperfusion of the lower extremities of rats. Ann Vasc Surg 20: 49-55. [Crossref]

52. Kosower BD, Christofidou SM, Sweitzer TD, Muro S, Buerk DJ, et al . (2003) Immunotargeting of catalase to the pulmonary endothelium alleviates oxidative stress and reduces acute lung transplantation injury. Nature Biotechnology 21: 392-398. [Crossref]

53. Wilhelm Filho D, Sell F, Ribeiro L, Ghisland M, Carrasquedo F, Fraga CG, Wallauer JP, Simões-Lopes PC, Uhart MM (2002) Comparison between the antioxidant status of terrestrial and diving mammals. Comp Biochem Physiol 133: 885-892. [Crossref]

54. Lindberg L, Sjöberg T, Ingemansson R, Steen S. (1996). Inhalation of nitric oxide after lung transplantation. Ann Thorac Surg 61:956-62.

Copyright: (C2017 Silva FM. This is an open-access article distributed under the terms of the Creative Commons Attribution License, which permits unrestricted use, distribution, and reproduction in any medium, provided the original author and source are credited. 